\title{
Increasing incidence of malignant mesothelioma after exposure to asbestos during home maintenance and renovation
}

\section{Nola J Olsen BAppSc, RGN, Senior Research Officer, School of Population Health \\ Peter J Franklin BSc(Hons) PostGradDipEnvSci, PhD, Research Assistant Professor, School of Population Health ${ }^{\top}$ \\ Alison Reid RGN, MSc, PhD, Research Associate Professor. Western Australian Institute for Medical Research'}

Nicholas H de Klerk BSc, MSc, PhD, Winthrop Research Professor, Centre for Child Health Research

Timothy J Threlfall MB BS, MPH, PhD, Principa Medical Officer and Manager $^{2}$

Keith Shilkin FRCPA, FCRPath, FHKCPath, Pathologist, School of Pathology and Laboratory Medicine

Bill Musk FRACP, MSc, MD, Clinica Professor, Respiratory Medicine $^{3}$

1 University of Western Australia, Perth, WA

2 Western Australian Cancer Registry, Department of Health Western Australia Perth, WA

3 Sir Charles Gairdne Hospital, Perth, WA nola.olsen@uwa.edu.au

MJA 2011; 195: 271-274 doi: 10.5694/mjall.10125

Editorial p 247 Reflections p 290 alignant mesothelioma (MM) of the pleura or peritoneum is a universally fatal disease predominantly caused by exposure to asbestos. In Australia, the incidence of MM has increased steadily since the early 1960s, initially affecting workers mining and milling raw asbestos and manufacturing asbestos products (the first wave), and then workers who used asbestos products in industry (the second wave). Over the past 20 years, there has been increasing concern about a third wave - people diagnosed with MM after short-term and/or lowlevel exposure to asbestos in the home or workplace. ${ }^{1}$ Home maintenance and renovation involving asbestos-containing building products is one of the activities most frequently associated with this third wave. It is a source of ongoing concern, given the widespread distribution of asbestos-containing products in homes and other buildings in Australian cities and towns.

Two forms of asbestos - serpentine (chrysotile or white asbestos) and amphibole (crocidolite or blue asbestos, and amosite or brown asbestos) - have been mined in and imported into Australia. Chrysotile was the main form of asbestos mined in Australia until crocidolite was mined at Wittenoom in the north of Western Australia, beginning in 1943 and continuing until 1966. More than $60 \%$ of the crocidolite produced was used in the manufacturing of asbestos cement products. For many years, Australia also imported both raw asbestos and manufactured asbestos goods. By 1954, Australia was ranked fourth among Western countries (after the United States, the United Kingdom and France) for gross consumption of asbestos cement products. However,

\begin{abstract}
Objective: To determine trends in incidence of malignant mesothelioma (MM) caused by exposure to asbestos during home maintenance and renovation.
\end{abstract}

Design, setting and participants: Using the Western Australian Mesothelioma Register, we reviewed all cases of MM diagnosed in WA from 1960 to the end of 2008 , and determined the primary source of exposure to asbestos. Categories of exposure were collapsed into seven groups: asbestos miners and millers from Wittenoom; all other asbestos workers; residents from Wittenoom; home maintenance/renovators; other people exposed but not through their occupation; and people with unknown asbestos exposure; or no known asbestos exposure. Latency periods and age at diagnosis for each group were calculated and compared.

Results: In WA, 1631 people (1408 men, 223 women) were diagnosed with MM between 1960 and 2008. Since 1981, there have been 87 cases ( 55 in men) of MM attributed to asbestos exposure during home maintenance and renovation, and an increasing trend in such cases, in both men and women. In the last 4 years of the study (2005-2008), home renovators accounted for $8.4 \%$ of all men and 35.7\% of all women diagnosed with MM. After controlling for sex and both year and age at diagnosis, the latency period for people exposed to asbestos during home renovation was significantly shorter than that for all other exposure groups, but the shorter follow-up and difficulty recalling when exposure first occurred in this group may partly explain this.

Conclusions: MM after exposure to asbestos during home renovation is an increasing problem in WA, and these cases seem to have a shorter latency period than other types of exposure. MM cases related to renovation will probably continue to increase because of the many homes that have contained, and still contain, asbestos building products.

on a per capita basis, Australia was top of the list. ${ }^{2}$

After World War II, asbestos cement products were commonly used as a building material in Australia. Asbestos cement products used in building include fibro sheeting; water, drainage and flue pipes; roofing shingles and guttering. Until the 1960s, $25 \%$ of all new homes were clad in asbestos cement. $^{2}$ The use of asbestos was slowly phased out in the 1970s and 1980s, but it is still found in structures built in the late 1980s. A total ban on the use of any type of asbestos was not introduced in Australia until 2003.

Direct occupational exposure to raw asbestos or asbestos products remains the predominant cause of MM, and the number of cases is not expected to peak until 2020. ${ }^{3}$ However, with the ban on mining and asbestos use, the number of occupational cases will decrease over the next 20-30 years. ${ }^{3}$ On the other hand, MM cases as a result of non-occupational exposure to asbestos are increasing, and there is little understanding of when, and at what level, this third wave will peak.

We describe here the changing trend in incidence of MM in WA, and the increasing numbers and relative proportions of people with MM whose exposure is unrelated to their occupation, especially those exposed to asbestos during home maintenance and renovation.

\section{Methods}

Cases were identified from the Western Australian Mesothelioma Register. The Register was formally established in 1982, although earlier 
1 Malignant mesothelioma in Western Australia, by exposure category and sex, 1960-2008

\begin{tabular}{lccc} 
Exposure category & Total cases (\%) & Men (\%) & Women (\%) \\
\hline Asbestos workers & & & \\
Wittenoom workers & $290(17.8 \%)$ & $270(19.2 \%)$ & $20(9.0 \%)$ \\
Other asbestos workers & $913(56.0 \%)$ & $896(63.6 \%)$ & $17(7.6 \%)$ \\
Non-occupational exposure & & & \\
Wittenoom residents & $58(3.6 \%)$ & $28(2.0 \%)$ & $30(13.5 \%)$ \\
Other non-occupational & $50(3.1 \%)$ & $13(0.9 \%)$ & $37(16.6 \%)$ \\
Home renovators & $87(5.3 \%)$ & $55(3.9 \%)$ & $32(14.3 \%)$ \\
Exposure source not identified & & & \\
No known & $75(4.6 \%)$ & $40(2.8 \%)$ & $35(15.7 \%)$ \\
Unknown & $158(9.7 \%)$ & $106(7.5 \%)$ & $52(23.3 \%)$ \\
Total & $1631(100 \%)$ & $1408(100 \%)$ & $223(100 \%)$
\end{tabular}

versions existed from 1960. Since 1960, when the first person was diagnosed with mesothelioma, every MM case in WA has been recorded, and these are now included in the Register. Each case has been reviewed at periodic meetings of the Western Australian Mesothelioma Register Committee, comprising a pathologist, an occupational physician, a respiratory physician, an epidemiologist, the manager of the Western Australian Cancer Registry and a research officer.

The WA Mesothelioma Register entry for each case includes age, sex, and date, as well as methods of diagnosis, histological type, site of disease, date of death, and available history of asbestos exposure. The written report of the pathologist responsible for the cytological or histopathological diag-

2 Malignant mesothelioma in Western Australia, by exposure category and calendar period, 1960-1964 to 2005-2008

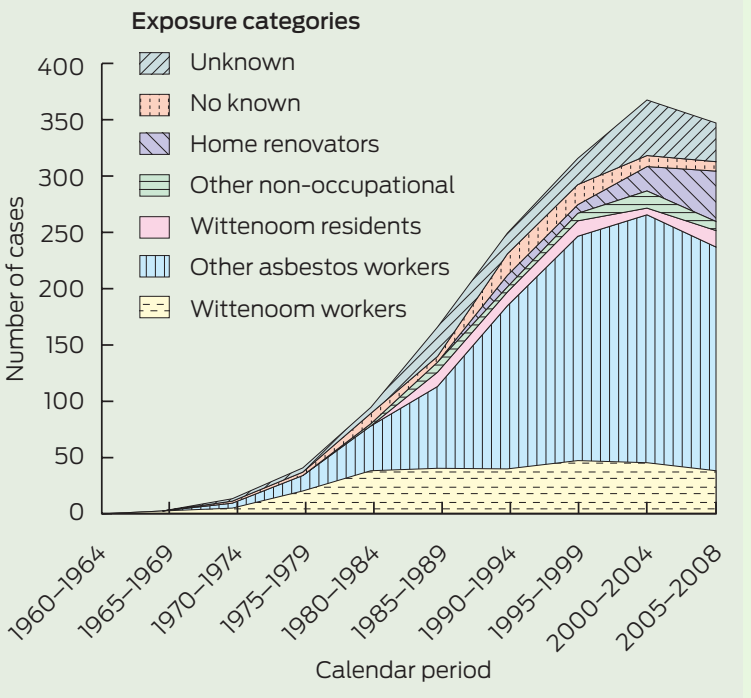

nosis of each case is reviewed to confirm the diagnosis and, in difficult cases, the original diagnostic material is reviewed by the Register's pathologist, and clinical and radiological information is also considered.

\section{Classification of exposure}

Until the late 1980s, a questionnaire detailing occupational and nonoccupational exposure to asbestos was completed for as many MM cases as possible. However, questionnaires are no longer used, and exposure information is gathered from sources such as clinical notes, doctors' letters, and advocacy groups. If possible, patients are still asked about occupational histories, including descriptions of tasks involving exposure to asbestos, as well as residential or other non-occupational exposure.

In reviewing each case, the Mesothelioma Register Committee seeks to classify the source of asbestos exposure. There are 29 exposure codes (22 occupational, five non-occupational, plus "unknown" and "no known"). "No known" exposure is coded if the person has been intensively questioned, but no source of exposure to asbestos can be identified. "Unknown" exposure is coded if the person has not been questioned at all, or if some source of asbestos exposure has been noted but sufficient details of the exposure are lacking. The five codes for different types of non-occupational or residential exposure include a code for "handyman, home maintenance and do-it-yourself (DIY)" exposure.

If there is more than one source of asbestos exposure, the committee considers the most significant exposure for coding, taking account of when the exposure occurred, and how much exposure was involved. For example, occupational exposure would usually be considered more significant than non-occupational exposure. To be coded as having "handyman, home maintenance and DIY" exposure means that no other source of exposure could be identified. In such cases, exposure has been during "participation in home renovations/home maintenance or as a bystander while such activities occurred". If possible the date of first exposure is also recorded; in some cases, the date of first exposure to any asbestos may be earlier than the date of the most significant exposure.

For this report, the coding was collapsed from 29 categories to seven. There were two occupational categories: asbestos miners and millers from Wittenoom (Wittenoom workers); and all other asbestos workers (other asbestos workers); three non-occupational categories: residents from the town of Wittenoom (Wittenoom residents); handyman, home maintenance and DIY (home renovators); and other types of non-occupational exposure (other non-occupational); and people whose exposure could not be identified (unknown) or who had no known exposure (no known).

\section{Statistical analyses}

MM cases coded as home renovators, for the whole group and separately for men and women, were grouped by sex, 5-year age-groups from 40 years onwards (with 85 and over as the oldest group), and 5-year periods from 1980 to the end of 2008 (except for the final 4-year period, 2005-2008).

A Poisson regression model was used to examine the changing trend in incidence over time. The log of the WA population was used as the offset variable in the model. Comparisons of age at diagnosis and latency periods between the five exposure groups two occupational and three nonoccupational - were calculated using linear regression, controlling for sex and year of diagnosis. Linear regression analyses were performed with SPSS version 17.1 (IBM, Armonk, NY, USA) and Poisson regression analyses 
with Stata version 10.1 (StataCorp, College Station, Tex, USA).

\section{Ethics approval}

The study was approved by the Department of Health WA Human Research Ethics Committee.

\section{Results}

Between 1960 and December 2008, there were 1631 cases of MM in WA (1408 men and 223 women), 1562 of whom have died. There were 1510 cases of pleural MM (1305 men), 114 cases of peritoneal MM (97 men) and seven cases of MM at other sites (six men).

Occupational exposures were the main source of exposure to asbestos for men $(82.8 \%)$ but not for women $(16.6 \%)$ (Box 1). There were about $10 \%$ of cases $(158 / 1631)$ with unknown exposure and about 5\% (75/1631) with no known exposure.

\section{Malignant mesothelioma and non- occupational asbestos exposure}

A total of 195 cases (96 men) were associated with non-occupational exposures. Fifty-eight cases (28 men) were ex-residents of Wittenoom, 87 (55 men) were home renovators and in 50 cases (13 men) their "other nonoccupational" exposure included visiting Wittenoom (15 [nine men]); living with an asbestos worker (22 [three men]) and various other residential exposures, such as dusting asbestos louvres or playing (as a child) in sheds used to store asbestos cement products (13 cases [one man]). For men, nonoccupational exposure accounted for $6.8 \%$ of all cases; for women, it accounted for $44.4 \%$ (Box 1 ).

The first case of MM associated with exposure attributed to home maintenance and renovation was registered in 1981. Of the 87 cases recorded, 55 men and 32 women, 84 had pleural MM (53 men) and three peritoneal MM (two men). There has been a steady increase in both the number and incidence rates of home maintenance/renovation cases since the mid 1980s (Box 2). Incidence rates for the last two periods (2000-2004 and 2005-2008) were significantly higher than the base rate (1980-1984) (Box 3, Box 4). For both men and women, home renovators now consti- tute the largest proportion of all nonoccupational cases. Between 2005 and $2008,8.4 \%$ of MM cases in men and $35.7 \%$ of those in women were attributed to home renovation.

After controlling for sex and both year and age at diagnosis, the latency period for home renovators was found to be significantly shorter than that for all other groups (Box 5). At diagnosis, home renovators were older than the people in the other two nonoccupational groups but slightly younger than those in the two occupational groups (Box 5).

\section{Discussion}

The number of cases of MM in WA is still increasing, although the number associated with occupational asbestos exposure appears to be reaching a plateau. However, MM cases associated with home maintenance and renovation have increased markedly over the past 10 years and remain on an upward trend. Most of the exposures reported in this group occurred in the 1960s and 1970s, but many WA homes still contain asbestos building products and home renovations have continued, and possibly increased, since that time. Therefore, the potential for MM cases from home renovation exposure to continue to increase remains a concern. It is not possible to predict for how long this increasing trend will continue, as there are no published data on past or current community exposure to asbestos.

Most MM cases attributed to home renovation have occurred in men, although this type of exposure as a proportion of all cases is much higher in women. For both men and women, there has been a marked increase in MM cases related to exposure from home maintenance and renovation over the past two decades. For men, the proportion of home renovation cases increased from about 3\% in the 1990 s to over $8 \%$ over the last 4 years of the study. For women, home renovation cases have increased from around $5 \%$ of all cases in the 1990s to over 35\% for the period 2005-2008. Of all known exposures, home maintenance and renovation is the main cause of MM in women. For men, occupational exposures remain the dominant cause of MM, but home maintenance and renovation is the most important non-occupational exposure.

To be included in the home renovator category, people had to have been exposed to asbestos either while performing simple renovations to their homes or, as family members, to have been exposed while these activities took place. The types of reported activities in this category included

\section{Age-adjusted increase in relative incidence rates of malignant mesothelioma attributed to asbestos exposure during home renovation - Western Australia}

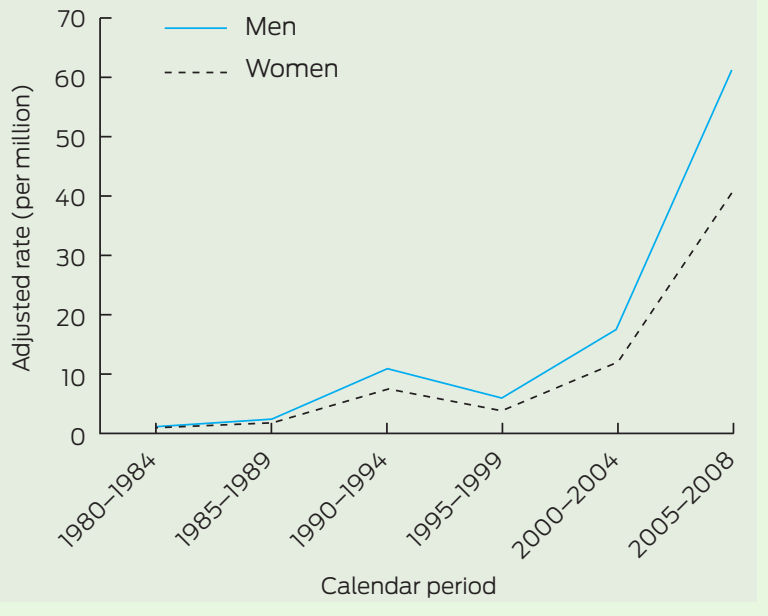

4 Relative change, 1980-1984 to 2005-2008, in incidence rates of malignant mesothelioma attributed to asbestos exposure during home renovation (adjusted for age and sex) - Western Australia

\begin{tabular}{lll} 
Period & $\begin{array}{c}\text { Incidence rate ratios } \\
(95 \% \mathrm{Cl})\end{array}$ & $P$ \\
\hline $1980-1984$ & 1.00 \\
$1985-1989$ & $1.87(0.17-20.59)$ & 0.610 \\
$1990-1994$ & $8.01(1.02-62.55)$ & 0.047 \\
$1995-1999$ & $4.16(0.50-34.59)$ & 0.187 \\
$2000-2004$ & $13.03(1.76-96.66)$ & $0.012^{*}$ \\
$2005-2008$ & $44.96(6.19-326.32)$ & $0.001 *$ \\
\hline
\end{tabular}

* Incidence rates for 2000-2004 and 2005-2008 are significantly higher than the base rate (1980-1984).

5 Adjusted mean latency period between exposure and diagnosis of malignant mesothelioma in Western Australia, by exposure category and mean age at diagnosis

\begin{tabular}{lcc} 
Exposure category & $\begin{array}{c}\text { Latency period, } \\
\text { years }(95 \% \mathrm{Cl})^{*}\end{array}$ & $\begin{array}{c}\text { Age at diagnosis, } \\
\text { years }(95 \% \mathrm{Cl})^{\dagger}\end{array}$ \\
\hline Wittenoom workers & $36.9(31.4-42.3)^{\ddagger}$ & $68.2(63.8-72.7)$ \\
Other asbestos workers & $39.8(34.3-45.2)^{\ddagger}$ & $70.4(66.1-74.7)$ \\
Wittenoom residents & $43.7(38.0-49.5)^{\ddagger}$ & $57.6(52.7-62.5)^{\ddagger}$ \\
Other non-occupational & $39.7(33.9-45.6)^{\ddagger}$ & $61.6(56.7-66.7)^{\ddagger}$ \\
Home renovators & $33.1(27.5-38.8)$ & $66.5(61.9-71.1)$
\end{tabular}

*Adjusted for sex, age at diagnosis and year of diagnosis. † Adjusted for sex and year of diagnosis. $¥$ Significantly different from home renovation group $(P<0.05)$. 
sanding asbestos cement walls in preparation for painting; lifting linoleum floors; replacing "tilux" (asbestos cement used in place of ceramic tiles) in bathrooms; and using asbestos cement sheeting for putting up fences and sheds, extending laundries, and enclosing verandas to create "sleep-outs". Some of these activities, particularly those involving the use of power tools, can produce short-term, high concentrations of asbestos fibres, ${ }^{4}$ and major renovation works may increase background fibre concentrations in the medium term, contributing to increased cumulative exposure. ${ }^{4}$ In most instances in this series, exposure was limited to a single task, which may have lasted for only a few days.

Based on reported first exposures, the home renovator group had the shortest estimated latency period. Latency periods have mostly been observed to be shorter in groups with occupational rather than non-occupational exposure. ${ }^{5-7}$ There are two reasons which may explain why we found a shorter latency period for MM cases with home renovation exposure. - First, there has been a shorter follow-up period of this group. Exposure in the home renovator group started in the 1960s, while exposure for the occupational groups commenced in the mid 1940s and early 1950s. As time from exposure increases so, necessarily, does the average latency period.

- Second, recalling when exposure first occurred is difficult, particularly for non-occupational exposures. This is likely to be reflected in the greater proportion of women, compared with men, who could not recall any asbestos exposure ("no known" exposure) (Box 1). This difficulty in recalling non-occupational exposures means that some patients may have been exposed to asbestos before the recorded renovation episode and therefore their latency period has been underestimated.

With the wide use of asbestos products in Australian homes after World War $\mathrm{II}^{2}$ the exact number of homes containing asbestos cement or other asbestos products is not known accurately. In one survey, $62.9 \%$ of homes in the Australian Capital Territory were found to contain asbestos. ${ }^{8}$ It was more common in older homes, with over $70 \%$ of homes built before 1965 containing asbestos, but was found in fewer than $1 \%$ of homes built after $1984 .^{8}$ A recent survey of Australian adults found that over $80 \%$ of respondents reported exposure to asbestos either at work or at home. ${ }^{9}$

Home renovation is a common activity in Australia. ${ }^{10,11}$ In a survey of home owners in Adelaide, major renovations were undertaken in about $34 \%$ of homes over a 5 -year period (1986-1991). ${ }^{11}$ Renovations were more common in older homes, particularly those over 50 years old. ${ }^{11}$ In the 10 -year period to $1999,66 \%$ of homes across Australia, built between 1920 and 1949 , had been renovated. ${ }^{10}$ In the Australian survey on potential asbestos exposure mentioned above, only about a third of respondents reported taking precautions to reduce exposure to asbestos fibres or dust in their homes. ${ }^{9}$ Although a Code of Practice for the safe removal of asbestos has been published, ${ }^{12}$ advice contained in the code is directed to owners of large buildings and asbestos removalists and not to small operators, individual tradesmen or home renovators. ${ }^{13}$

Our study confirms the rising trend in diagnosis of MM resulting from exposure to asbestos during renovation activities in and around the home. The continued widespread distribution of asbestos cement products in WA homes, and the long latency period between exposure and diagnosis of MM, means that there is likely to be a further increase in cases of MM attributable to home renovations.

Competing interests: No relevant disclosures.

Received 7 Feb 2011, accepted 11 Jul 2011.

1 Landrigan PJ. The third wave of asbestos disease: exposure to asbestos in place. Public health control. Introduction. Ann N Y Acad Sci 1991; 643: $\mathrm{XV}$-Xvi.

2 National Occupational Health and Safety Commission. The incidence of mesothelioma in Australia 1999 to 2001, Australian Mesothelioma Register Report 2004. 16th report. Canberra: NOHSC, 2004. http://safeworkaustralia.gov.au/ AboutSafeWorkAustralia/WhatWeDo/ Publications/Documents/47/Australian Mesothelioma_Register_Report_2004_Archived PDF.pdf (accessed Jul 2011).

3 Leigh J, Davidson P, Hendrie L, Berry D. Malignant mesothelioma in Australia, 1945-2000. Am J Ind Med 2002; 41: 188-201.

4 Brown SK. Asbestos. In: Spengler JD, Samet JM, McCarthy JF, editors. Indoor air quality handbook. New York: McGraw-Hill Professional, 2001: 38.138.17.

5 Bianchi C, Giarelli L, Grandi G, et al. Latency periods in asbestos-related mesothelioma of the pleura. Eur J Cancer Prev 1997; 6: 162-166.

6 Marinaccio A, Binazzi A, Cauzillo G, et al. Analysis of latency time and its determinants in asbestos related malignant mesothelioma cases of the Italian register. Eur J Cancer 2007; 43: 2722-2728.

7 Reid A, Heyworth J, de Klerk NH, Musk B. Cancer incidence among women and girls environmentally and occupationally exposed to blue asbestos at Wittenoom, Western Australia. Int J Cancer 2008; 122: 2337-2344.

8 Howell M. ACT asbestos surveys - health risk assessment. Final report. ACT Asbestos Taskforce. Canberra: URS Pty Ltd, 2005. http:// www.asbestos.act.gov.au/resources/pdfs/ Asbestos_Health_Risk_08_05.pdf (accessed Jul 2011).

9 Howat P, Jalleh G, Lin C, et al. Residential exposure to asbestos: implications for public health. Proceedings of the 39th Annual Conference of the Public Health Association of Australia; 2009; Sep 28-30; Canberra. ISBN 9781-8-75990-28-3.

10 Australian Bureau of Statistics. Australian social trends 2002. Canberra: ABS, 2002. (ABS Cat. No. 4102.0.)

11 Baum S, Hassan R. Home owners, home renovation and residential mobility. J Sociol 1999; 35: 23-41.

12 National Occupational Health and Safety Commission. Code of practice for the safe removal of asbestos. 2nd ed. Canberra: NOHSC, 2005. http://www.safeworkaustralia.gov.au/ AboutSafeWorkAustralia/WhatWeDo/ Publications/Documents/234 SafeRemoval\%20ofAsbestos2nd Edition NOHSC 2002_2005.pdf (accessed Jul 2011).

13 Bromwich D. The 2005 Australian Asbestos Codes of Practice: an occupational hygiene perspective. J Occup Health Saf Aust NZ 2006; 22: 463-470. 